\title{
¿EXISTE POTENCIALIDAD DEL SERVICIO EN LA TASA-ARBITRIO?
}

\author{
THERE POTENTIAL OF SERVICE RATE - WILL?
}

\section{Teodoro Castro Contreras*}

Doctorando de la Facultad de Ciencias Contables de la UNMSM

[Recepción: Marzo de 2011/ Conformidad: Abril de 2011]

\section{RESUMEN}

La dialéctica o contradicción del tributo, en su esencia más abstracta, podría formularse de este modo: el tributo presupone la propiedad privada, porque sólo puede tributar el propietario de bienes raíces, de bienes muebles o de bienes indeterminados, expresados en papel moneda, es decir el sujeto del "hecho imponible"; pero al mismo tiempo, pone en tela de juicio (y desde luego, limita y recorta en la práctica) el mismo núcleo de la propiedad privada, gracias al cual la institución del tributo existe y puede seguir existiendo ${ }^{1}$.

Esta reflexión, desarrollada en el plano filosófico, nos permite percibir que la institución denominada tributo, también es de interés de quienes se mueven en este complejo territorio.

En nuestro país, El Texto Único Ordenado del Código Tributario, aprobado por Decreto Supremo No 135-99-EF (publicado el 19 de Agosto de 1,999) ha optado por la clasificación tripartita, para efectos de desarrollar el concepto de las especies tributarias, es así que, según el la Norma II del Título Preliminar reconoce: Impuesto, Contribución y Tasa. Esta última se subdivide en: Arbitrios, Derechos y Licencias.

Palabras clave: Especies tributarias, contribución y tasa, propiedad privada, código tributario.

\begin{abstract}
The dialectic of the tribute or contradiction in its abstract essence, could be formulated as follows: the tax presupposes private property, because only the owner may be taxed as real estate, personal property or of indefinite assets expressed in paper money is that the subject of "taxable event" but at the same time, it puts into question (and of course, limits and cuts in practice) the very core of private property, through which the institution of the tax exists and may continue exist.

This reflection, developed at the philosophical level, we can perceive that the institution called the tribute is also of interest to those who move in this complex area.

In our country, the Consolidated Text of the Tax Code, approved by Supreme Decree N o 135-99-EF (published on August 19 of 1,999$)$ chose the tripartite classification for purposes of developing the concept of species tax is so, according to Rule II of the introduction acknowledges, Tax, Tax and Rate. The latter is subdivided into: Means, Rights and Licenses.
\end{abstract}

Key words: Species of taxation, contributions and tax, property, tax code.

* CPC. Doctorando por la UNMSM, Socio de la firma Venero \& Asociados Contadores Públicos, Profesor de tributación de la UNMSM

E- mail: trigosegado@hotmail.com

1 BUENO OVIEDO, Gustavo, El tributo en la Dialéctica sociedad Política/Sociedad Civil. El Basilisco, 2a época, No 33, páginas 3-24. 


\section{INTRODUCIÓN}

1. ¿Es posible que las municipalidades cobren arbitrios sin que el servicio sea prestado de manera efectiva en el contribuyente?

2. ¿La potencialidad del servicio, para efecto de los arbitrios, debe ser un componente básico que justifique su cobro?

El presente trabajo pretende realizar un pequeño estudio sobre el tema de la referencia (Potencialidad del Servicio en la Tasa Arbitrio), procurando analizarlo desde la Sentencia emitida por el Tribunal Constitucional.

\section{POTENCIALIDAD DEL SERVICIO EN LA TASA-ARBITRIO}

Llama nuestra atención el concepto que el Código Tributario le asigna a la Tasa: "Es el tributo cuya obligación tiene como hecho generador la prestación efectiva por el Estado de un servicio público individualizado en el contribuyente" y a la sub especie Arbitrios: "Son tasas que se pagan por la prestación o mantenimiento de un servicio público"

El artículo $66^{\circ}$ del TUO de la Ley de Tributación Municipal señala: "Las tasas municipales son los tributos creados por los Concejos Municipales cuya obligación tiene como hecho generador la prestación efectiva por la Municipalidad de un servicio público o administrativo reservado a las Municipalidades de acuerdo con la Ley Orgánica de Municipalidades".

El literal "a" del artículo $68^{\circ}$ dice: "Tasas por servicios públicos o arbitrios: son las tasas que se paga por la prestación o mantenimiento de un servicio público individualizado en el contribuyente"
Por su parte el segundo párrafo del artículo $69^{\circ}$ del TUO de la Ley de Tributación Municipal dispone que "La determinación de las obligaciones referidas en el párrafo anterior deberán sujetarse a los criterios de racionalidad que permitan determinar el cobro exigido por el servicio prestado, basado en el costo que demanda el servicio y su mantenimiento, así como el beneficio individual prestado de manera real y/o potencial".

Reiteradas Resoluciones del Tribunal Fiscal (RTF) entre las que tenemos a la Jurisprudencia 1273-4-2002 de fecha 08 de marzo del 2002, este organismo establece: “...mediante Resolución No 14276, este Tribunal dejó establecido que la obligación de pago de arbitrios no se genera en el hecho que el contribuyente, personal y directamente disfrute del servicio, sino que es suficiente que el Concejo lo tenga organizado, aún cuando algún vecino no lo aproveche directamente, porque el servicio es prestado en la Jurisdicción, lo que beneficia también al recurrente, por lo que carece de sustento su argumento en el sentido que no recibe de manera individualizada los servicios al no tener en la circunscripción colindante a su negocio parque alguno ni contar con un servicio de seguridad ciudadana, jardinero o personal de limpieza para su negocio, ello sin perjuicio, de que aquél esté facultado a canalizar sus inquietudes respecto a la calidad de los servicios brindados al órgano competente de la Municipalidad".

La sentencia No 053-2004-PL/TC del Pleno Jurisdiccional del Tribunal Constitucional, de fecha 25 de mayo de 2005, estableció en su Fundamento "C" Imprecisiones en la Definición Legal del Arbitrio ${ }^{3}$ : "Tomando en cuenta esta última referencia, este Tribunal aprecia dos aspectos contradictorios:

2 Artículo sustituido por el Artículo 24 del Decreto Legislativo No 952, publicado el 3 de febrero de 2004.

3 Párrafos 4to y 5to.

18/ QVIPURAMAYOC | Vol. 18(35) 20101 
1) Si en la determinación se admite un beneficio potencial, entonces no podría afirmarse al mismo tiempo y en todos los casos una real prestación efectiva de servicios, pues puede que esta se dé o no se dé; y por otro lado, 2) Si hablamos de beneficio individual, el mismo debería constatarse en todos los casos de manera concreta y efectiva; sin embargo, como veremos más adelante, hay factores que imposibilitan esta comprobación.

Debido a cuestiones fácticas derivadas de la propia naturaleza del arbitrio, lo correcto sería considerar que tal beneficio individual puede darse de manera directa (real) $y / o$ indirecta (potencial), conforme se explicará seguidamente."

Héctor Villegas 4 , sostiene, sobre la potencialidad que: “...la noción de tasa que propugnamos conceptúa que su hecho generador se integra con una actividad que el Estado cumple y que está vinculada con el obligado al pago. La actuación estatal vinculante es quizá el elemento caracterizador más importante para saber si al enfrentarnos a determinado tributo estamos realmente ante una tasa. Sobre esto la doctrina y jurisprudencia son coincidentes. La Corte Suprema de la nación ha sostenido que es de la naturaleza de la tasa que su cobro corresponda siempre a la concreta, efectiva e individualizada prestación de un servicio relativo al contribuyente (...) Esta actividad debe ser efectivamente prestada $y$ no puede ser meramente potencial. En tal sentido, concordamos con Jarach, quien al analizar el Modelo de Código Tributario para América Latina afirma que le parece inaceptable que la tasa pueda justificarse en un servicio individualizado pero meramente potencial, agregando que tal doctrina ha sido la defensa esgrimida habitualmente por los municipios de la República Argentina para justificar los recaudos por servicios no prestados"

Indudablemente la doctrina es producto de pensadores agudos que reflexionan sobre diferentes tópicos, en este específico caso, sobre la tasa arbitrio; sin embargo, lo que no podemos obviar es la advertencia que hace el Tribunal Constitucional, cuando emite la Sentencia arriba descrita (Sentencia No 0532004-PL/TC) y nos dice al respecto:

"1. El arbitrio y la confluencia de intereses: beneficio particular y beneficio colectivo

Si bien, teóricamente, la tasa sirve para financiar servicios públicos divisibles, en la práctica el arbitrio (subespecie) presenta problemas técnicos para justificar su cobro para servicios perfectamente divisibles. No siempre se podrá verificar esta contraprestación efectiva de servicio público individualizado; ello tiene como consecuencia que el vecino contribuyente, al no constatar la existencia de un beneficio directamente individualizado en su caso, se muestre renuente a aceptar el aumento del costo.

Y es que, en realidad, no resulta posible, en todos los casos, lograr el ideal de paridad efectiva en el intercambio, cual suerte de obligación bilateral entre el contribuyente y el municipio, situación que básicamente se debe a la confluencia de intereses particulares (coste divisible) y generales (coste indivisible), comunes en la prestación de servicios esenciales de carácter municipal, a diferencia de lo que ocurre, por ejemplo, en el caso del otorgamiento de una licencia municipal, donde el contribuyente-solicitante sí puede constatar de modo particular el beneficio de recibir la licencia municipal, por la cual,

4 Notable estudioso argentino doctrinario del derecho tributario. 
la municipalidad fija un costo concretizado como consecuencia de la actividad administrativa desplegada para ello.

La esencialidad del servicio municipal, en el caso de los arbitrios de limpieza pública, ornato y seguridad ciudadana, hace que su exigencia trascienda al beneficio directo y/o concretizado (individualización). Efectivamente, en los servicios esenciales de carácter municipal, al confluir tanto la utilidad singular como la colectiva, no siempre podrá apelarse a un beneficio directo, sino más bien a uno indirecto cuando prioritariamente sea la comunidad la beneficiaria directa.

Quedan claras, entonces, las dificultades técnicas existentes para la concreción del beneficio individual en todos los casos, siendo más propio admitir que tal beneficio individual pueda verificarse tanto de manera directa como indirecta.

En vista de ello, el Tribunal Constitucional exhorta al legislador para que, atendiendo a esta situación, redefina la materia considerando estas particularidades, de modo que, a futuro, pueda sincerarse y asumirse la confluencia del beneficio particular y el beneficio general de un modo más adecuado, generando, a su vez, mayor aceptación y conciencia entre los contribuyentes sobre lo que deberán pagar."

Hemos querido transcribir todo el párrafo a efectos de poder entender en conjunto cual es la posición de custodio de la norma fundamental sobre esta singular subespecie tributaria, llegando a concluir que de acuerdo a lo expresado por César García Novoa ${ }^{5}$ : El respeto a la apariencia legal es fuente de certeza, en tanto exime de analizar el régimen jurídico de esa categoría” agregando que: "El recurso a un nomen iuris se hace bajo el presupuesto de que tal nomen se empleará para denominar al realidad normativa que responde a las características que de la categoría nombrada ha fijado la tradición jurídica”

Es decir que las denominaciones que emplee el legislador, deben corresponder a la aplicabilidad objetiva de los acontecimientos; caso contrario se estaría, peligrosamente, rebasando los principios contenidos en el artículo $74^{\circ}$ de la norma fundamental.

Los procesos de amparo que se han activado en Perú para cuestionar el cobro de este tributo, todos han sido declarados infundados; sin embargo, en la Sentencia que analizamos en las líneas precedentes, existe un elemento que no se ha tomado en cuenta por el legislador y que podría devenir en NULO todos los procesos donde el contribuyente con justa razón ha impugnado el cobro por servicios que no se le han prestado de manera individualizada.

Básicamente nos estamos refiriendo al numeral "5" del Fallo: "Exhortar al Congreso para que haga las precisiones correspondientes a la figura del arbitrio, conforme se ha señalado en la presente Sentencia”.

Hasta el momento los legisladores no han emitido ninguna norma que sirva para precisar la figura de Arbitrio, manteniéndose tal cual desde la última modificación realizada con el Decreto Legislativo No 952 y esta no se encuentra referida a la potencialidad del servicio en la tasa arbitrio; sino que esta direccionada a la aplicación terminológica que terminaría la discusión existente, cuando dice: "Debido a cuestiones fácticas derivadas de la propia naturaleza del arbitrio, lo correcto sería considerar que tal beneficio individual puede darse de manera directa (real) $y / o$ indirecta (potencial), conforme se explicará seguidamente."

5 García Novoa, César. El Concepto de Tributo. Tax Editor SA. Pág. 320. 
Podemos inferir entonces que el Tribunal Constitucional ha querido que con una norma aclaratoria se modifique la parte final del segundo párrafo del artículo $69^{\circ}$ del TUO de la Ley de Tributación Municipal, cambiando los conceptos "directa" por real e "indirecta" por potencial, con lo cual, indudablemente, se aclararía el panorama y se evitarían procesos costosos y prolongados.

No está demás reflexionar sobre que ocurre cuando el legislador no cumple con lo exhortado por el Tribunal Constitucional?, se produce acaso un vacío legal que puede ser aprovechado por los contribuyentes para exigir (vía proceso de amparo) que efectivamente la potencialidad es un término tan abierto que no satisface lo que ocurre en el plano fáctico?

\section{CONCLUSIONES}

1. Lamentablemente el legislador no se ha preocupado por seguir las recomendaciones del Tribunal Constitucional, pese a que desde la fecha en que se emitiera (25 de mayo de 2005), han transcurrido casi Seis (6) años.

2. La desidia del legislador ha puesto en riesgo la seguridad jurídica puesto que si los deudores tributarios (contribuyentes) activaran procesos de amparo para reclamar sobre el cobro de ésta especie tributaria, encontrarían terreno fértil para sus reflexiones.
3. Es necesario que a través de una ley aclaratoria, se sustituyan los términos recomendados por el custodio de la norma fundamental, a efectos de la precisa aplicabilidad del nomen iuris.

4. Las instituciones que se han visto afectadas por el cobro de estos tributos (por servicios que nunca fueron prestados de manera individualizada), encontrarían la posibilidad de que el Tribunal Constitucional replantee sus Sentencias dándoles la razón frente a una demanda de Amparo bien fundamentada.

\section{AGRADECIMIENTO}

Deseo expresar mi agradecimiento al Dr. Raúl Arrarte, por la invitación a presentar mi artículo de investigación denominado: EXISTE POTENCIALIDAD DEL SERVICIO EN LA TASA-ARBITRIO?

\section{REFERENCIAS BIBLIOGRÁFICAS}

1. BUENO OVIEDO, Gustavo, El tributo en la Dialéctica sociedad Política/Sociedad Civil. El Basilisco, 2a época, No 33, páginas 3-24.

2. Artículo sustituido por el Artículo 24 del Decreto Legislativo No 952, publicado el 3 de febrero de 2004.

3. García Novoa, César. El Concepto de Tributo. Tax Editor SA. Pág. 320. 